\title{
Viability of Lactobacillus acidophilus ATCC 4356 incorporated into ice cream using three different methods
}

\author{
Ayse Asci Arslan ${ }^{1}$ Emine Mine Comak Gocer ${ }^{1}$. \\ Muammer Demir ${ }^{1}$ - Zeynep Atamer ${ }^{2}$. \\ Joerg Hinrichs $^{2}$ • Ahmet Kücükcetin ${ }^{1}$
}

Received: 25 August 2015 / Revised: 15 February 2016 / Accepted: 23 February 2016 /

Published online: 16 March 2016

(C) INRA and Springer-Verlag France 2016

\begin{abstract}
Although ice cream is a good vehicle to convey probiotics to human hosts, probiotics are not stable in ice cream because of milieu conditions, species- and product-related properties. Studies on the incorporation of probiotics into ice cream have been conducted; however, there is a need for development of a production method in which probiotics maintain their viability and the physicochemical properties of ice cream are preserved. In this study, the aim was to compare the physicochemical properties of ice cream containing Lactobacillus acidophilus (ATCC 4356) that was incorporated using different methods, as well as to determine the viability of L. acidophilus in the samples. Ice cream was produced using three methods: method 1 , ice cream mix was fermented with $L$. acidophilus prior to freezing; method 2, milk ( $10 \%$ of total milk used in the preparation of ice cream mix) was taken and subsequently fermented with L. acidophilus; the fermented milk was introduced to the remaining ice cream mix prior to freezing; and method 3, L. acidophilus was added to the ice cream mix and the mix was not fermented with L. acidophilus prior to freezing. The viability of L. acidophilus in ice cream was better for methods 1 and 2 of ice cream production when compared to method 3. The viable counts after 90 days of storage were higher than the target level $\left(>10^{6} \mathrm{cfu}^{-\mathrm{g}^{-1}}\right)$ only in samples produced using methods 1 and 2 .
\end{abstract}

Keywords Ice cream $\cdot$ Probiotics $\cdot$ Survival $\cdot$ Production method

Ahmet Kücükcetin

kucukcetin@akdeniz.edu.tr

1 Department of Food Engineering, Faculty of Engineering, Akdeniz University, Dumlupinar Boulevard, Campus, 07058 Antalya, Turkey

2 Institute of Food Science and Biotechnology, Department of Dairy Science and Technology, University of Hohenheim, Stuttgart, Germany 


\section{Introduction}

In recent years, there has been a growing interest in probiotic food products due to their nutritional value and health-promoting properties. Probiotic microorganisms need to survive throughout food processing and storage, and subsequently during gastric transit in order to show their probiotic properties (Heller 2001; Casarotti and Penna 2015). In order to achieve the claimed beneficial effects of probiotic bacteria, these specific microorganisms must be viable, active, and abundant in the product up to the expiry date (cell counts range from $10^{6}$ to $10^{9} \mathrm{cfu}^{-1} \mathrm{~g}^{-1}$ (Casarotti and Penna 2015). The dose that reaches the target site in the body plays an important role in the development of the characteristic effects of probiotic bacteria (Sanders and Huis In't Veld 1999). Therefore, strains used in probiotic foods and food formulas need to be resistant to harsh storage conditions and digestive juices, as well as bile salts. Furthermore, they must show the ability to attach themselves to the interior of the intestinal wall. Among dairy products, ice cream is known to be an ideal product for the delivery of probiotic bacteria to the human host (Cruz et al. 2009; Ferraz et al. 2012; Soukoulis et al. 2014). However, temperature change, also referred to as "cold shock", during freezing and melting may cause damage such as reduction or even complete loss of metabolic activity (Haynes and Playne 2002; Mohammadi et al. 2011).

Several reasons have been described as contributors to poor survival of probiotics: (i) milieu conditions (availability of nutrients, growth promoters, and inhibitors, concentration of sugars, incubation temperature, and fermentation time), (ii) species (interactions between species present, level of inoculation), and (iii) product-related conditions (increasing acidity, chemical composition of the product, storage temperature) (Heller 2001; Nousia et al. 2011).

There is a strong demand for the development of a standard processing method that can result in high concentrations of probiotic strains in the product and maintaining probiotic functions at a maximum level. In a study of different production methods (non-fermented ice cream), Abghari et al. (2011) demonstrated that some probiotic behaviors (bile and acid resistance) of the bacteria were affected by ice cream processing. Our hypothesis in this study was that the survival of probiotic bacteria in ice cream could be improved by the application of an appropriate production technique, since adaptation of probiotic bacteria to adverse environmental conditions such as osmotic stress during production can affect their survival. Different studies on the incorporation of probiotic bacteria into ice cream and similar products have been reported (e.g., Hekmat and McMahon 1992; Abghari et al. 2011). However, to our knowledge, no study has been conducted that evaluates the applied incorporation methods with respect to probiotic viability in the samples as well as physiochemical properties of the ice cream. Hence, in this study different methods for the manufacture of ice cream containing L. acidophilus as probiotic bacteria were applied. The physicochemical and microbiological characteristics of the ice cream samples were determined.

\section{Materials and methods}

\subsection{Bacteria and growth conditions used in the production of probiotic ice cream}

The reference strain, L. acidophilus ATCC 4356, that was used for all experiments was obtained from the DSMZ (German Collection of Microorganisms and Cell Cultures 
$\mathrm{GmbH}$, Braunschweig, Germany). This strain is reported to be an important inhabitant of the gastrointestinal tract (Palomino et al. 2015) and therefore commonly used in probiotic studies. One $\mathrm{mL}$ of de Mann Rogosa, and Sharpe (MRS) broth (Merck, Darmstadt, Germany) was added to the pure culture of L. acidophilus in its original ampoule and the contents was stirred; this suspension was added to $250 \mathrm{~mL}$ of MRS broth and incubated at $37{ }^{\circ} \mathrm{C}$ for $48 \mathrm{~h}$. After incubation, the medium was centrifuged $\left(6000 \mathrm{~g}, 5{ }^{\circ} \mathrm{C}, 5 \mathrm{~min}\right)$. The pellet was then re-suspended in $5 \mathrm{~mL}$ sterile nutrientglycerol mixture [0.8 g nutrient broth (Merck), $30 \mathrm{~mL}$ glycerol and $70 \mathrm{~mL}$ pure water]. It was aliquoted into 1-mL micro-centrifuge tubes (T-6524, Sigma-Aldrich Company Ltd., Dorset, United Kingdom) and immediately frozen at- $80{ }^{\circ} \mathrm{C}$.

\subsection{Raw materials}

Raw cow's milk was provided by the Dairy Processing Unit of the Faculty of Agriculture at Akdeniz University. The milk used for ice cream production was skimmed to $0.1 \%(w / w)$ fat.

\subsection{Ice cream manufacturing process}

Probiotic ice cream was prepared using three different methods for the incorporation of probiotic bacteria (Fig. 1). For each incorporation method, the inoculation was performed in a way that ensured a final concentration of approximately $10^{8}-10^{9} \mathrm{cfu}^{-\mathrm{g}^{-1}}$ of L. acidophilus in the ice cream mix. The raw milk used for all ice cream production was heated at $121{ }^{\circ} \mathrm{C}$ for $10 \mathrm{~min}$ in a WAC-60 autoclave (Daihan Scientific Co. Ltd., Seoul, Korea) and mixed with cream, milk powder, saccharose, and stabilizer to result in an

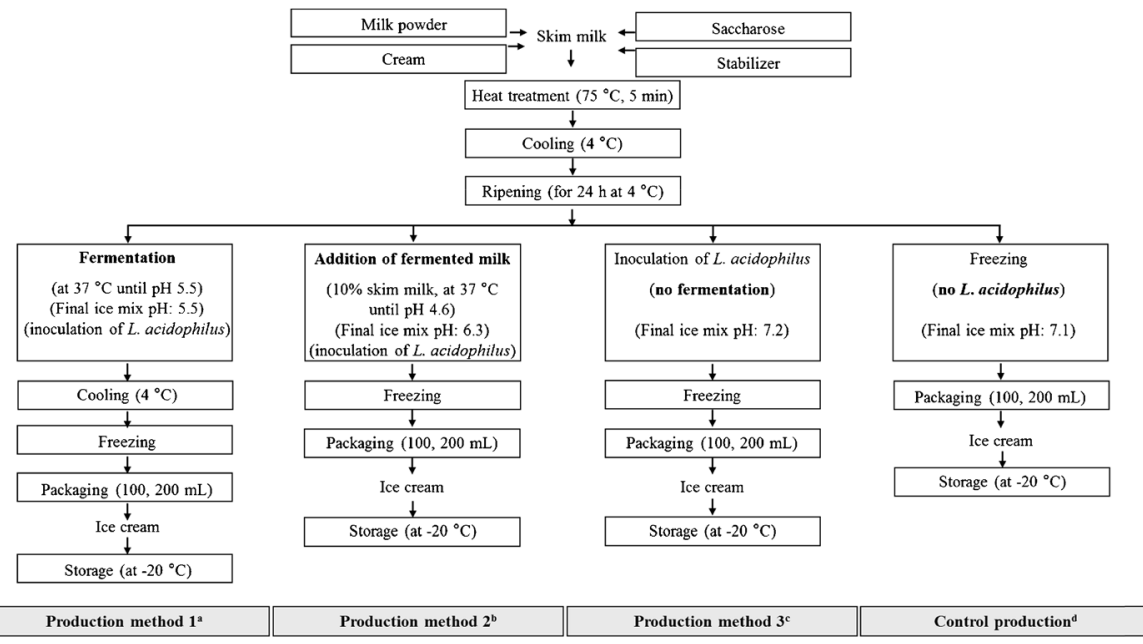

Fig. 1 Three different methods for the production of probiotic ice cream and the production of control samples. ${ }^{a}$ Method 1: ice cream mix was fermented with L. acidophilus ATCC 4356 prior to freezing, ${ }^{b}$ method 2: milk ( $10 \%$ of total milk used in preparation of ice cream mix) was taken and then was fermented with L. acidophilus ATCC 4356; the fermented milk was introduced to the ice cream mix prior to freezing, ${ }^{\mathrm{c}}$ method 3: L. acidophilus ATCC 4356 was added to ice cream mix and the mix was not fermented with L. acidophilus prior to freezing, and ${ }^{\mathrm{d}}$ control production: ice cream without L. acidophilus ATCC 4356 
ice cream formulation containing 1\% $(w / w)$ milk fat, $18 \%(w / w)$ saccharose, $10 \%(w / w)$ nonfat milk solids, and $0.5 \%(w / w)$ stabilizer (salep, which was purchased from a supplier in Antalya, Turkey). The mixture was heated at $75^{\circ} \mathrm{C}$ for $5 \mathrm{~min}$ and then cooled to $4{ }^{\circ} \mathrm{C}$ for all methods. It was then left to ripen at $4{ }^{\circ} \mathrm{C}$ for $24 \mathrm{~h}$. For the first method, the mix was warmed up to $37^{\circ} \mathrm{C}$ after ripening. The mix was then inoculated with $L$. acidophilus and fermented until a $\mathrm{pH}$ of 5.5 was reached. After fermentation, the mix was cooled to $4{ }^{\circ} \mathrm{C}$, followed by freezing. For the second method, $10 \%$ of the milk used in the preparation of the ice cream mix was taken and fermented with L. acidophilus at $37^{\circ} \mathrm{C}$ until a pH of 4.6 was reached. The fermented milk was cooled to $4{ }^{\circ} \mathrm{C}$, and then added to the remaining ice cream mixture before freezing ( $\mathrm{pH}$ of final $\operatorname{mix}=6.3$ ). For the third method, L. acidophilus in 1-mL micro-centrifuge tubes was directly inoculated to the ice cream mixture in order to have a final concentration of L. acidophilus in the ice cream mix of approximately $10^{8}-10^{9} \mathrm{cfu}^{-1} \mathrm{~g}^{-1}$ after ripening at $4{ }^{\circ} \mathrm{C}$ for $24 \mathrm{~h}$. The mix was not fermented prior to freezing. Along with the ice cream samples produced using these three mentioned incorporation methods, ice cream with and without (taken as control samples) L. acidophilus was produced based on a modified method by Guner et al. (2007) for the experiments. The probiotic ice cream samples were produced by using an M10C batch freezing machine with a $10 \mathrm{~kg}$ capacity (Mehen Food Machine Manufacture Co. Ltd., Nanjing, China). The samples were packaged in $200 \mathrm{~mL}$ cups and stored at $-20{ }^{\circ} \mathrm{C}$ for three months. All experiments were conducted in triplicate.

\subsection{Physicochemical analysis}

Dry solid content $(\%)$, fat content $(\%)$, protein content $(\%)$, and titratable acidity $(\%)$ of the ice cream mixes and the raw milk used for the production of the ice cream were determined using gravimetric, Gerber, Kjeldahl and titration methods, respectively (VDLUFA 2003). Percentage of titratable acidity for the ice cream samples was measured by the method of Bradley et al. (1993). The $\mathrm{pH}$ values of the milk, ice cream mixtures, and ice cream samples were measured using a $\mathrm{pH}$ meter (Thermo Scientific Orion 2-Star, Bremen, Germany).

The viscosity values of the mixes used for ice cream production were measured using a Brookfield viscometer (model DV-II+; Brookfield Engineering Laboratories, Inc., Stoughton, MA) and the method described by Abd El-Rahman et al. (1997) after $24 \mathrm{~h}$ of ripening at $4{ }^{\circ} \mathrm{C}$, using spindle 2 , and speed of $1 \mathrm{rpm}$. Increase in volume (overrun) was determined using a $100 \mathrm{~mL}$ cup and Eq. (1) described by MartinouVoulasiki and Zerfiridis (1990).

$$
\% \text { Overrun }=\frac{\text { Net wt of cup of mix-Net wt of cup of ice cream }}{\text { Net wt of cup of ice cream }}
$$

Meltdown was estimated according to El-Nagar et al. (2002) with slight modifications. For the measurement of meltdown, $100 \mathrm{~g}$ of tempered samples were left to melt (at a constant temperature $20.0 \pm 0.1^{\circ} \mathrm{C}$ ) on a 2.5 - $\mathrm{mm}$ wire mesh screen above a beaker. The weight of drip was measured over a 60 min period.

Firmness of ice cream samples stored for 1, 30, 60, and 90 days was analyzed using a texture analyzer (TA-XT- Plus, Stable Micro Systems, Surrey, UK). Samples were 
analyzed according to the method described by Aime et al. (2001). Four measurements using a cylindrical probe/plunger attachment (acrylic material, $2.5 \mathrm{~cm}$ in diameter, and $3.5 \mathrm{~cm}$ in height) were conducted to determine the firmness. The speed of penetration for the attachment into the ice cream was set $2 \mathrm{~mm} . \mathrm{s}^{-1}$. Texture Expert software program was used for analysis of the measured data.

\subsection{Microbiological analysis}

Bacterial counts were determined before freezing and after frozen storage of $1,15,30$, 60 , and 90 days (at $-20^{\circ} \mathrm{C}$ ). Ice cream mix and ice cream samples $(1 \mathrm{~g})$ were decimally diluted in $9 \mathrm{~mL}$ ringer solution (1/4). One $\mathrm{mL}$ aliquot dilutions were poured on MRS agar (Merck). The pour plate technique was used. All plates were incubated anaerobically at $37{ }^{\circ} \mathrm{C}$ for $72 \mathrm{~h}$ in an anaerobic jar (Merck) using an anaerobic gas pack system (Anaerocult ${ }^{\circledR}$ Merck). The results were expressed as colony-forming units per gram (cfu.g ${ }^{-1}$ ) of sample (Anonymous 1997).

\subsection{Statistical analysis}

In this study, each variation of production and storage for probiotic ice cream was performed in triplicate. All statistical calculations were performed using SAS Statistical Software (release for Windows, SAS Institute Inc., Cary, NC, USA). A two-factor ANOVA was conducted to determine the effects of production method and storage time on physicochemical properties of probiotic ice cream and viability of L. acidophilus used in manufacture of ice cream. Duncan's multiple range test was conducted to detect the differences among the treatment means for the measured characteristics of probiotic ice cream.

\section{Results and discussion}

\subsection{Physicochemical characteristics}

The chemical composition of the raw milk used in the production of ice cream samples was: pH $6.63 \pm 0.15$, titratable acidity (lactic acid \%) $0.19 \pm 0.02 \%$, dry matter 8.7 $\pm 0.4 \%$, protein $4.3 \pm 0.3 \%$, and fat $3.6 \pm 0.1 \%$. The $\mathrm{pH}$ and titratable acidity values of both probiotic ice cream mixes and ice cream samples are given in Table 1 . The dry matter content and viscosity values of the ice cream mixes ranged between 29 and $32 \%$ and between $18 \mathrm{~s}$ and $28 \mathrm{~Pa}$.s, respectively. When average fat content of the samples was considered, no difference $(P>0.05)$ was observed among the samples $(0.9 \%$ fat $)$.

It was observed that different production methods had a significant influence $(P<0.05)$ on the viscosity of ice cream mixes (Table 1$)$. The lowest viscosity was observed for samples produced using method 3; however, no significant difference $(P>0.05)$ was detected between the viscosity values for samples produced using method 3 and the control sample. The observed high viscosity values for samples produced using methods 1 and 2 can be explained by the fermentation step. The probiotic bacteria could produce exopolysaccharides during fermentation (Patel et al. 2010) that could result in an increase in the viscosity of these products. 


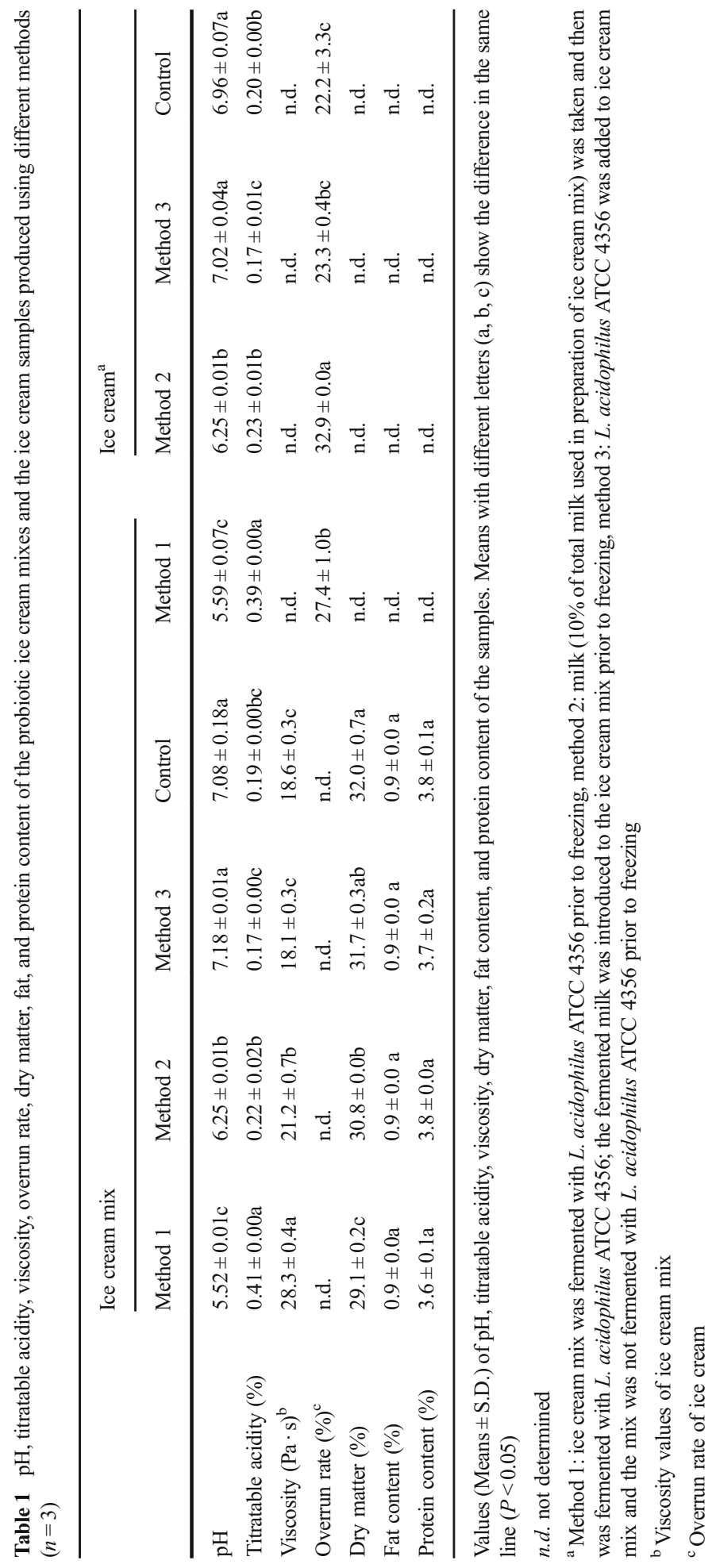


Firmness values of the ice cream samples during 90 days of storage are illustrated in Fig. 2. The highest firmness values for probiotic ice cream samples were obtained for the samples produced using method 3; however, no significant difference $(P>0.05)$ was found between the sample produced using method 3 and the control sample. The decrease in firmness values observed for samples produced using methods 1 and 2 was due to the low total solids in the ice cream mixes. Firmness increased significantly for all products with extension of storage time. Akalin and Erişir (2008) also reported higher firmness values for ice cream samples as the storage time was increased.

Table 1 summarizes the percent overrun rates of the ice cream samples for the three methods. Percent overrun rates ranged between 22.2 and $32.9 \%$. The highest overrun rates were obtained for samples produced using method 2, followed by methods 1 and 3 which were not significantly different from each other. The higher overrun obtained for method 2 is related to greater air content (Sofjan and Hartel 2004). The stability of food foams, in this case ice cream, is affected by air bubble size, distribution and volume fraction, as well as by the air/water tension and $\mathrm{pH}$ (Miquelim et al. 2010). In this study, the low observed overrun rates for samples produced using method 3 could explain the high firmness values for these samples.

The melting properties of ice cream samples throughout storage is given in Fig. 3 for all the samples. Melting properties were measured during a 60 -min period. When compared to the control samples, no significant change in meltdown was observed for ice cream samples with $L$. acidophilus at the beginning and end of the storage period. For all samples, the meltdown decreased as storage time increased. Similar observations were also reported by Akalin and Erişir (2008). The least melting was observed for the samples produced using method 2. This can be attributed to the highest observed overrun rates of the samples produced using method 2 (Table 1). Sakurai et al. (1996) and Sofjan and Hartel (2004) also showed that ice cream samples with lower

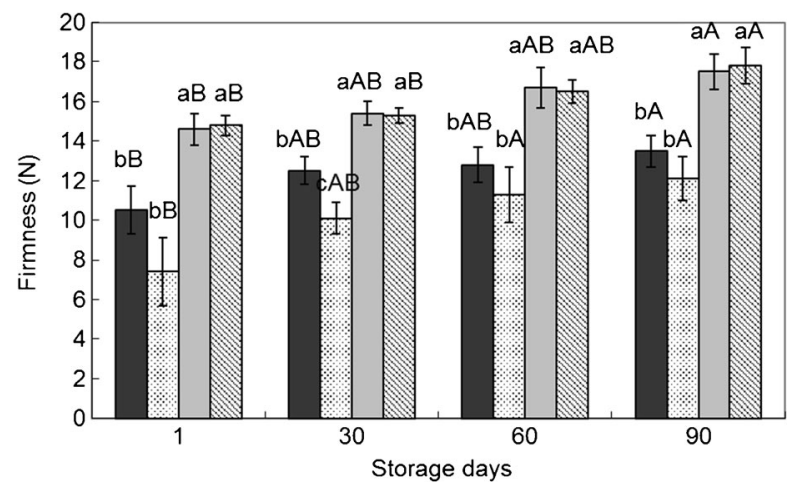

Fig. 2 Firmness of ice cream samples during storage. ice cream produced with the method 1: ice cream mix was fermented with L. acidophilus ATCC 4356 prior to freezing, $\therefore$. ice cream produced with the method 2: milk ( $10 \%$ of total milk used in preparation of ice cream mix) was taken and then was fermented with L. acidophilus ATCC 4356; the fermented milk was introduced to the ice cream mix prior to freezing, $\square$ ice cream produced with the method 3: L. acidophilus ATCC 4356 was added to ice cream mix and the mix was not fermented with $L$. acidophilus ATCC 4356 prior to freezing, control sample: ice cream without L. acidophilus ATCC 4356. The bars represent mean values, and the error bars represent standard deviation of the mean. Means with different small letters $(a, b, c)$ in the different bars at the same storage day are significantly different $(P<0.05)$. Means with different capital letters $(A, B)$ in the same bars are significantly different $(P<0.05)$ 
overrun rates melt more rapidly. However, when meltdown was considered, no significant differences $(P>0.05)$ were found between the samples during storage except for at day 60 . The lowest meltdown was observed for samples produced using method 2; however, no significant differences $(P>0.05)$ were detected between the meltdown for samples produced using methods 1 and 2 .

\subsection{Microbiological analysis}

The cell count (in log units) of $L$. acidophilus in ice cream mixes varied between 7.5 and $8.8 \mathrm{cfu}^{-1} \mathrm{~g}^{-1}$. The changes in viable counts found in the ice cream samples during storage are shown in Table 2. When freezing the mix, a decrease of between 0.1 to $3.5 \mathrm{log}$ units of L. acidophilus was observed. The lowest and highest decreases were observed for the ice cream samples produced using method 1 and in the samples produced using the method 3, respectively, during 90 days storage. A decline in L. acidophilus counts after freezing could be a result of cold stress during freezing and osmotic stress due to the high amount of saccharose in the products (Mohammadi et al. 2011). Furthermore, it should be noted that the pre-adaptation of $L$. acidophilus against these stresses due to the fermentation step applied to the ice cream mix may provide protection to the probiotic cells in the ice cream samples produced using method 1. Streit et al. (2008) found that acid adaptation of cells of Lactobacillus debrueckii subsp. bulgaricus allowed the cells more resistant to cold stress. They referred this as a cross-protection phenomenon, since the resistance to a given stress (e.g., cold stress) was improved by applying a different stress beforehand (e.g., acid stress). Similar observations were also reported in the studies conducted using cells of Lactobacillus rhamnosus GG (Ampatzoglou et al. 2010). The log counts of L. acidophilus in the ice cream

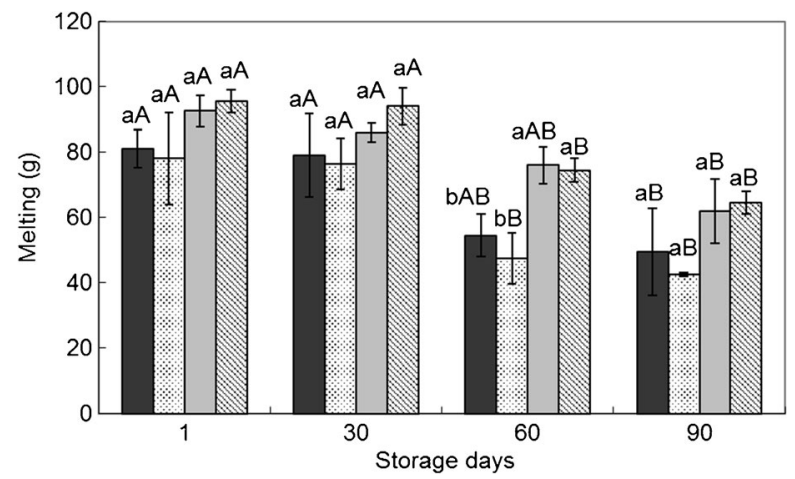

Fig. 3 Melting properties of ice cream during storage. $\quad$ ice cream produced with the method 1: ice cream mix was fermented with L. acidophilus ATCC 4356 prior to freezing, 7 ice cream produced with the method 2: milk ( $10 \%$ of total milk used in preparation of ice cream mix) was taken and then was fermented with L. acidophilus ATCC 4356; the fermented milk was introduced to the ice cream mix prior to freezing, $\square$ ice cream produced with the method 3: L. acidophilus ATCC 4356 was added to ice cream mix and the mix was not fermented with L. acidophilus ATCC 4356 prior to freezing, control sample: ice cream without L. acidophilus ATCC 4356. The bars represent mean values, and the error bars represent standard deviation of the mean. Means with different small letters $(a, b)$ in the different bars at the same storage day are significantly different $(P<0.05)$. Means with different capital letters $(A, B)$ in the same bars are significantly different $(P<0.05)$ 
Table 2 Viable counts of Lactobacillus acidophilus in the ice cream samples during storage $(n=3)$

\begin{tabular}{|c|c|c|c|c|c|c|}
\hline \multirow[t]{3}{*}{ Ice cream ${ }^{\mathrm{a}}$} & \multicolumn{6}{|c|}{ Viable count $\left(\log _{10}\right.$ cfu.g $\left.\mathrm{g}^{-1}\right)$} \\
\hline & \multirow[t]{2}{*}{ Ice cream mix } & \multicolumn{5}{|c|}{ Ice cream during storage } \\
\hline & & 1st day & 15 th day & 30th day & 60th day & 90th day \\
\hline Method 1 & $7.5 \pm 0.2 \mathrm{bA}$ & $7.1 \pm 0.2 \mathrm{bAB}$ & $7.1 \pm 0.0 \mathrm{aAB}$ & $7.0 \pm 0.3 \mathrm{aB}$ & $6.8 \pm 0.1 \mathrm{aBC}$ & $6.5 \pm 0.1 \mathrm{aC}$ \\
\hline Method 2 & $8.7 \pm 0.2 \mathrm{aA}$ & $8.6 \pm 0.1 \mathrm{aA}$ & $6.9 \pm 0.0 \mathrm{aB}$ & $6.8 \pm 0.0 \mathrm{aB}$ & $6.4 \pm 0.1 \mathrm{aBC}$ & $6.0 \pm 0.4 \mathrm{aC}$ \\
\hline Method 3 & $8.8 \pm 0.2 \mathrm{aA}$ & $5.3 \pm 0.4 \mathrm{cB}$ & $4.4 \pm 0.3 \mathrm{bC}$ & $4.3 \pm 0.0 \mathrm{bC}$ & $3.4 \pm 0.3 \mathrm{bD}$ & $3.2 \pm 0.0 \mathrm{bD}$ \\
\hline
\end{tabular}

Values (Means \pm S.D.) of L. acidophilus count of the samples. Means with different small letters (a, b, c) show the difference in the same column $(P<0.05)$. Means with different capital letters $(\mathrm{A}, \mathrm{B}, \mathrm{C})$ show the difference in the same line $(P<0.05)$

${ }^{a}$ Method 1: ice cream mix was fermented with L. acidophilus ATCC 4356 prior to freezing, Method 2: milk $(10 \%$ of total milk used in preparation of ice cream mix) was taken and then was fermented with L. acidophilus ATCC 4356. The fermented milk was introduced to the ice cream mix prior to freezing, Method 3: L. acidophilus ATCC 4356 was added to ice cream mix and the mix was not fermented with L. acidophilus ATCC 4356 prior to freezing

samples after one day and 90 days storage ranged between 5.3 and $8.6 \mathrm{cfu}^{-\mathrm{g}^{-1}}$ and between 3.2 and $6.5 \mathrm{cfu} . \mathrm{g}^{-1}$, respectively. Over 90 days, total loss in the ice cream samples produced using method 1 was only $0.6 \mathrm{log}$ units, with an initial loss of $0.4 \log$ units at day 1. However, this loss was quite different from the losses observed for methods 2 (total loss of 2.6 logs over this period) and 3 (total loss of $2.1 \operatorname{logs}$ over this period). It is seen that there is a large drop in cell counts when comparing samples produced using methods 2 and 3 to those from method 1. Heller (2001) reported that the physiological state of the bacteria plays a very important role in the termination of fermentation. It is indicated that bacteria taken from the logarithmic phase are more susceptible to environmental stresses than those taken from the stationary phase. In our study, the difference observed for the counts of L. acidophilus in the ice cream samples produced using methods 1 and 2 was due to the differences in the physiological states of L. acidophilus. The counts of L. acidophilus in ice cream samples produced using method 3 were lower than those produced using methods 1 and 2 after frozen storage of 1, 15, 30, 60, and 90 days. Unlike methods 1 and 2, L. acidophilus used in method 3 had no time for multiplication. Higher counts of L. acidophilus were observed in the day one samples produced using method 2 than the day one samples produced using method 1. However, no differences $(P>0.05)$ were found between the samples produced using methods 1 and 2 at the end of the storage. Acidity of the product has been claimed to be one reason for the loss of probiotic bacteria viability in frozen fermented dairy products (Shah and Ravula 2000). However, in our study L. acidophilus grew to high numbers in the ice cream mix used for method 1 because of the relatively high $\mathrm{pH}$ value for the ice cream mix $(\mathrm{pH}=5.52)$. Other authors also reported such a decrease during storage (Akalin and Erişir 2008; Hekmat and McMahon 1992). During the entire storage period, the measured probiotic counts in all ice cream samples were higher than or equal to the target, $10^{6}$ cfu.g ${ }^{-1}$, except for samples produced using method 3 . However, one has to 
keep in mind that these observations are valid only for ice cream samples stored at $-20{ }^{\circ} \mathrm{C}$ for 3 months.

\section{Conclusion}

The investigations in this work show that freezing of the ice cream mix after a fermentation step with L. acidophilus (method 1) and freezing after inoculation of the mix with the fermented milk (separately fermented with L. acidophilus) (method 2) did not make a difference regarding the physicochemical properties. However, freezing directly after inoculation of $L$. acidophilus without a fermentation step (method 3 ) yielded differences in the ice cream samples compared to those produced using methods 1 and 2. After 90 days of storage the number of viable L. acidophilus in ice cream samples produced using methods 1 and 2 was higher than the target level. Methods 1 and 2 can be applied for the production of probiotic ice cream, whereas it is more difficult to maintain target bacterial counts in ice cream produced without a fermentation step (method 3). Additional research is required to determine in vivo properties of probiotics used in ice cream production. Moreover, further studies regarding consumer expectations are also of significant importance.

Acknowledgments This research project was supported by the Scientific and Technological Research Council of Turkey (TUBITAK) and The Scientific Research Projects Coordination Unit of Akdeniz University. The authors would like to acknowledge the technical assistance of Sibel Milci. They also would like to thank Anisa Loewen for proofreading the manuscript.

\section{Compliance with ethical standards}

Conflict of interest The authors declare that they have no conflict of interest.

\section{References}

Abd El-Rahman AM, Madkor SA, Ibrahim FS, Kilara A (1997) Physical characteristics of frozen desserts made with cream, anhydrous milk fat, or milk fat fractions. J Dairy Sci 80:1926-1935

Abghari A, Sheikh-Zeinoddin M, Soleimanian-Zad S (2011) Nonfermented ice cream as a carrier for Lactobacillus acidophilus and Lactobacillus rhamnosus. Int J Food Sci Technol 46:84-92

Aime DB, Arntfield SD, Malcolmson LJ, Ryland D (2001) Textural analysis of fat reduced vanilla ice cream products. Food Res Int 34:237-246

Akalin AS, Erişir D (2008) Effects of inulin and oligofructose on the rheological characteristics and probiotic culture survival in low-fat probiotic ice cream. J Food Sci 73:M184-M188

Ampatzoglou A, Schurr B, Deepika G, Baipong S, Charalampopoulos D (2010) Influence of fermentation on the acid tolerance and freeze drying survival of Lactobacillus rhamnosus GG. Biochem Eng J 52:65-70

Anonymous (1997) Dairy Starter cultures of lactic acid bacteria (LAB) standart of identity, vol 149A. International IDF Standart Belgium

Bradley RL, Arnold E, Barbano DM, Semerad RG, Smith DE, Vines BK (1993) Chemical and physical methods. In: Standard methods for the examination of dairy products. APHA, Washington, DC

Casarotti SN, Penna ALB (2015) Acidification profile, probiotic in vitro gastrointestinal tolerance and viability in fermented milk with fruit flours. Int Dairy J 41:1-6 
Cruz AG, Antunes AEC, Sousa ALOP, Faria JAF, Saad SMI (2009) Ice-cream as a probiotic food carrier. Food Res Int 42:1233-1239

El-Nagar G, Clowes G, Tudorica CM, Kuri V, Brennan CS (2002) Rheological quality and stability of yog-ice cream with added inulin. Int J Dairy Technol 55:89-93

Ferraz JL, Cruz AG, Cadena RS, Freitas MQ, Pinto UM, Carvalho CC, Faria JAF, Bolini HMA (2012) Probiotic bacteria in ice cream produced with different overrun levels. J Food Sci 71(1):S24-S28

Guner A, Ardic M, Keles A, Dogruer Y, Dogruer Y (2007) Production of yogurt ice cream at different acidity. Int J Food Sci Technol 42:948-952

Haynes IN, Playne MJ (2002) Survival of probiotic cultures in low-fat ice-cream. Aust J Dairy Technol 57:10 14

Hekmat S, McMahon DJ (1992) Survival of Lactobacillus acidophilus and Bifidobacterium bifidum in ice cream for use as a probiotic food. J Dairy Sci 75:1415-1422

Heller KJ (2001) Probiotic bacteria in fermented foods: product characteristics and starter organisms. Am J Clin Nutr 73:374S-379S

Martinou-Voulasiki IS, Zerfiridis GK (1990) Effect of some stabilisers on textural and sensory characteristics of yogurt ice cream from sheep milk. J Food Sci 55:703-707

Miquelim JN, Lannes SCS, Mezzenga R (2010) pH influence on the stability of foams with proteinpolysaccharide complexes at their interfaces. Food Hydrocoll 24:398-405

Mohammadi R, Mortazavian AM, Khosrokhavar R, Da Cruz AG (2011) Probiotic ice cream: viability of probiotic bacteria and sensory properties. Ann Microbiol 61:411-424

Nousia FG, Androulakis PI, Fletouris DJ (2011) Survival of Lactobacillus acidophilus LMGP-21381 in probiotic ice cream and its influence on sensory acceptability. Int J Dairy Technol 64:130-136

Palomino MM, Allievi MC, Martin JF, Waehner PM, Acosta MP, Rivas CS, Ruzal SM (2015) Draft genome sequence of the probiotic strain Lactobacillus acidophilus ATCC 4356. Genome Announc 3(1):e0142114

Patel AN, Michaud P, Singhania RR, Soccol CR, Pandey A (2010) Polysaccharides from probiotics: new developments as food additives. Food Technol Biotechnol 48:451-463

Sakurai K, Kokubo S, Hakamata K, Tomita M, Yoshida S (1996) Effect of production conditions on ice cream melting resistance and hardness. Milchwissenschaft 51:451-454

Sanders ME, Huis In’t Veld J (1999) Bringing a probiotic-containing functional food to the market: microbiological, product, regulatory and labeling issues. Anton van Leeuw 76(1-4):293-315

Shah NP, Ravula RR (2000) Microencapsulation of probiotic bacteria and their survival in frozen fermented dairy desserts. Aust J Dairy Technol 55:139-144

Sofjan RP, Hartel RW (2004) Effects of overrun on structural and physical characteristics of ice cream. Int Dairy J 14:255-262

Soukoulis C, Fisk ID, Bohn T (2014) Ice cream as a vehicle for incorporating health-promoting ingredients: conceptualization and overview of quality and storage stability. Compr Rev Food Sci Food Saf 13:627655

Streit F, Delettre J, Corrieu G, Beal C (2008) Acid adaptation of Lactobacillus delbrueckii subsp. bulgaricus induces physiological responses at membrane and cytosolic levels that improves cryotolerance. J Appl Microbiol 105:1071-1080

VDLUFA (2003) Handbuch der landwirtschaftlichen Versuchs-und Untersuchungsmethodik, Methodenbuch Band VI-Chemische, physikalische und mikrobiologische Untersuchungsverfahren für Milch Milchprodukte und Molkereihilfsstoffe. VDLUFA-Verlag, Darmstadt 